Bio-grafia: Escritos sobre la Biologia y su Enseñanza Vol 4 No6 ISSN 2027-1034. Primer semestre de 2011, Bogotá, Colombia, pp 35-50.

\title{
LA BOTÁNICA EN EL MARCO DE LAS CIENCIAS NATURALES: DIVERSAS MIRADAS DESDE EL SABER PEDAGÓGICO. ${ }^{1}$
}

\section{BOTANY IN THE CONTEXT OF THE NATURAL SCIENCES: DIVERSE LOOKS FROM THE PEDAGOGICAL KNOWLEDGE.}

Por: Deysi Serrato Rodriguez ${ }^{2}$

\begin{tabular}{|l|}
\hline Recibido: 17-03-2011 \\
\hline Aceptado: 07-07-2011 \\
\hline
\end{tabular}

\section{RESUMEN}

La enseñanza de la botánica se ha visto atravesada por el discurso de la interdisciplinariedad de las ciencias, las competencias científicas y la primacía de otros saberes útiles en contexto, entre otros aspectos que han llevado a pensar que ésta no se enseña, por tal razón, es pertinente indagar a través de los trayectos de práctica, cómo se aborda lo botánico en la escuela tomando como eje principal los saberes pedagógicos que circulan en los maestros que enseñan Biología alrededor de la botánica, ésta desde del marco de las ciencias naturales. Es así, que para lograr visibilizar dichos saberes se recurrió a la mirada arqueológica -genealógica, donde se realizó el rastreo de algunos documentos institucionales e investigativos, las charlas con cinco maestros en torno a su ser y quehacer y el análisis de los anteriores elementos desde la relación sujeto, saber y poder. Con base en lo anterior, se encontró que en la escuela circulan algunos saberes relacionados con la Botánica, los cuales son trabajados desde aspectos taxonómicos y netamente Biológicos. Además, de visibilizarse que en las instituciones educativas y maestros con los que se trabajó conciben la enseñanza de la Botánica, se como un pretexto que contribuye a desarrollar determinadas competencias científicas en la escuela.

Palabras Claves: saber pedagógico, maestro, botánica, enseñanza.

\section{ABSTRACT}

1 Trabajo desarrollado en el marco de la práctica pedagógica realizada en la línea de investigación Trayectos y Aconteceres: estudios del ser y quehacer del maestro desde la pedagogía. 2010 II. Proyecto asesorado por Angélica Osorio

2 Estudiante IX semestre Licenciatura en Biología. Línea de investigación Trayectos y Aconteceres Estudios del Ser y el Quehacer del Maestro desde la Pedagogía. Universidad Pedagógica Nacional. Correo: deysi.sro@gmail.com 
Botany teaching has been crossed by the discourse of interdisciplinarity of sciences, scientific competences and the primacy of other useful knowledge in context, among other aspects that have made think that it is not taught. For this reason, it is pertinent to inquire through the ways of practice, how to tackle botany in the school taking as main axis the pedagogical knowledge that Biology Teachers have about botany, from the framework of natural sciences. Thus, to show such knowledge, the archaeological-genealogical look was used, where the tracking of some institutional and researchable documents were carried out, conversations with five teachers about their being and task and the analysis of the above items from the relation subject, knowledge and power. Based on the foregoing, it was found that some knowledge related to botany circulates in the school, which is worked from aspects purely taxonomical and biological. In addition to, it was evident that educational institutions and teachers with whom we worked conceive the teaching of botany as an excuse that is helping to develop scientifics skills at school.

Key Words: Pedagogical knowledge, teacher, botany, teaching.

\section{INTRODUCCIÓN}

El maestro se caracteriza por ser un intelectual que mediante la reflexión de su práctica pedagógica y la integración de la investigación a su labor, cuestiona y problematiza aspectos relacionados con la enseñanza, la escuela y los sujetos, logrando la constitución y consolidación de aquel saber que le es propio y que se manifiesta en su quehacer de enseñar.

Dicho saber al cual se hace referencia, es aquel que el maestro construye a través de su práctica pedagógica, el saber pedagógico, que está conformado por diversos discursos a propósito de la enseñanza en su sentido práctico y conceptual, en donde el maestro es "el soporte de un saber especifico circunscrito a las prácticas que tienen lugar en las prácticas de saber... prácticas con las cuales entra en relación la enseñanza."(Zuluaga, 1999, p. 14) un saber que le proporciona autoridad y credibilidad al maestro al momento de reestructurar y resignificar las prácticas de enseñanza, en este caso específicamente de las relacionadas con el acercamiento a lo botánico, pues tal y como lo afirma Zuluaga (1999) “... no existe saber sin una práctica definida y toda práctica puede definirse por el saber qué forma." p. 66

Es así, que remitirse al saber pedagógico conlleva a explorar e indagar aspectos prácticos de la enseñanza, la escuela y el maestro, al igual que contribuye a preguntarse por las condiciones de existencia de determinados saberes que atraviesan la escuela y por los diversos factores que permean la práctica pedagógica del maestro y es que "La práctica pedagógica se inscribe en el saber pedagógico, mostrando tal saber como el conjunto de conocimientos cotidianos o elaborados, de conceptos, de métodos, de prescripciones y de observaciones provenientes de la interioridad misma del saber, así como de decisiones 
externas a él. De este modo, la práctica pedagógica juega un papel más de aliada que de subordinada al interior del saber pedagógico." (Zuluaga, et al. 2006,p. 26)

De acuerdo a lo anterior, surge el interés de indagar sobre los saberes pedagógicos que circulan en los maestros que enseñan Biología alrededor de la botánica en el marco de las ciencias naturales, pues si bien ésta no es mencionada como tal en los currículos, algunos saberes relacionados con ella son enseñados en la escuela. Por consiguiente, en ésta circulan "...un conjunto de saberes relacionados con el "objeto de estudio: planta" pero no necesariamente en el marco de la botánica." (Osorio et al. 2009). Lo anterior conlleva a pensar en la existencia de unas relaciones de fuerza y saber que determinan qué enseñar y cómo, evidenciándose posiblemente un desplazamiento de la botánica en el currículo por otros saberes más útiles en el contexto laboral en el que se esperan desempeñar los estudiantes.

Así mismo, lo que circula alrededor de la botánica en la escuela está ligado a las posibilidades que los maestros generan a partir de lo que acontece dentro y fuera del aula, de ahí la importancia de conocer los saberes pedagógicos que los maestros construyen en torno a la botánica, pues probablemente sean estos los que posibiliten preguntarse qué formas de enseñanza permiten involucrar la botánica en el aula, y cuál es la relación de este saber con los sujetos.

Es así, que es importante dirigir la mirada hacia la enseñanza de la botánica y con ello lograr visibilizar los saberes pedagógicos que circulan en los maestros de Biología alrededor de ésta, lo que permite preguntarse por el lugar de la botánica en la escuela y reconocer las prácticas de enseñanza relacionadas con ésta. Pues actualmente, a través de diversas estrategias y proyectos pensados desde el MEN como "Expediciones Botánicas Siglo $X X I^{\prime \prime}$ se han trabajado aspectos concernientes a la botánica pero con el propósito de lograr el desarrollo de competencias científicas.

\section{MATERIALES Y MÉTODOS}

Para el desarrollo y consolidación del proyecto se contó con la colaboración de dos Licenciadas en Biología que ejercen su profesión en el colegio CAFAM, dos Licenciadas en Biología y Química del I.E.D Bravo Páez y una Licenciada en Biología del Gimnasio La Arboleda. Dichos maestros que participaron en la investigación laboran en instituciones donde se realizó la practica pedagógica y donde se habían realizado otros tipos se acercamientos en semestres anteriores. Además se recurrió al rastreo de documentos de índole teórico e investigativo e institucionales. 
En primera instancia es necesario dar a conocer las categorías que fueron claves para el abordaje del proyecto planteado, siendo estas: botánica, saber pedagógico y enseñanza y los conceptos metodológicos que permitieron el desarrollo de estas categorías fueron el sujeto, el saber y el poder. De acuerdo a lo anterior, se recurre a la mirada arqueológica genealógica para posibilitar la consolidación del proyecto, ésta "Se constituye en una mirada diferente de los acontecimientos, fuera de las relaciones causa-efecto, la linealidad de la historia y los discursos hegemónicos. Propone entonces visibilizar los acontecimientos, la lectura hipertextual de los enunciados, el análisis de las fuerzas y las formas de saber que les subyacen, y esto a través de la conformación de un archivo que contenga documentos de distinta índole, desde los de circulación popular, hasta documentos institucionales, legales y políticos" (Roa y Herrera, 2010, p.15)

Por consiguiente, en primera medida se elaboró el triángulo de relaciones entre el saber, el sujeto y el poder (Ver Figura 1) A partir de este, se logró evidenciar que el poder y el saber están vinculados, pues el saber constituye relaciones de poder y “...ejercer el poder crea objetos

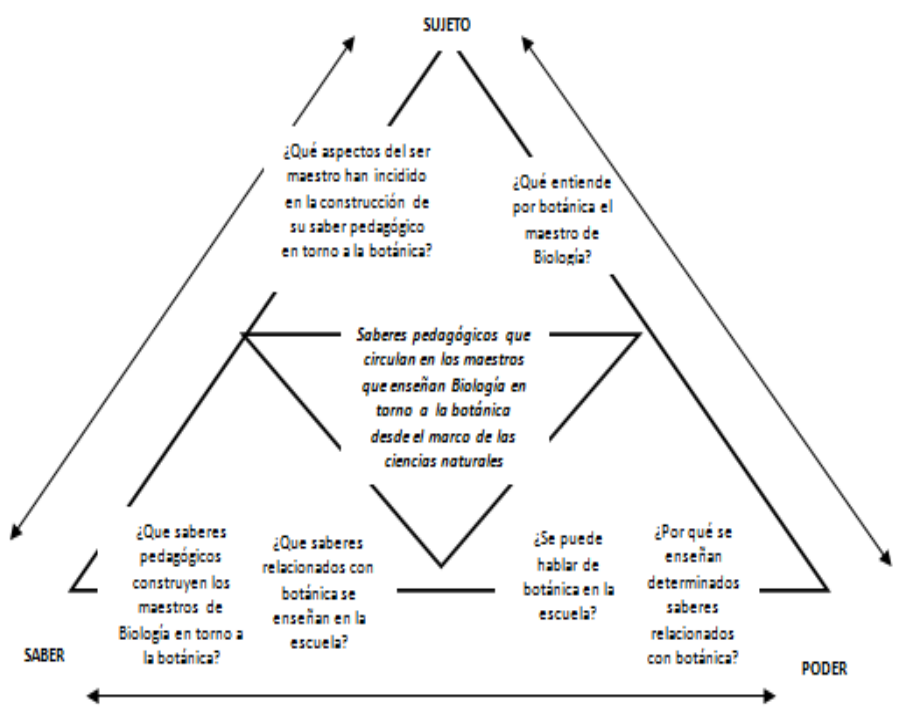

Figura 1. de saber, los hace emerger..." (Lugo, 2002, p. 22.). Sin embargo, es importante aclarar que a pesar de la estrecha relación entre el saber y el poder cada uno tiene sus particularidades, es así, que parafraseando a Deleuze (1987) el saber se basa en relaciones de formas, es estratificado y archivado, por el contrario, el poder se basa en relaciones de fuerza y es diagramático. Por lo tanto, al ser el poder el ser resultado de diversas fuerzas, éste está en todas partes, atravesando al sujeto el cual no puede ser considerado independientemente de ellas, pues éstas lo subjetivan y condicionan. Es así, que el sujeto es aquel lugar donde las relaciones de poder y saber convergen.

De acuerdo a lo anterior, se logró establecer una serie de vínculos que dan cuenta de las posibles dinámicas que se presentan en el ámbito educativo, social, político y económico, y que probablemente posibilitan la construcción y circulación de un saber en torno a la botánica en la escuela.

Es así, que existen unas condiciones de posibilidad para el saber pedagógico que construye el maestro en torno a la botánica, un saber condicionado por relaciones de poder, éste no es pensado como algo que se posee y se transmite sino como relaciones de 
fuerza que se ejercen, relaciones que a su vez, generan resistencias, que incitan o provocan. De este modo, lejos de pensar al poder como algo represivo, el poder es activo, es decir, produce sujetos. Es así, que el poder atraviesa todo el entramado social y se ejerce, no verticalmente, sino en redes formadas por un conjunto heterogéneo de elementos discursivos o no discursivos.

Por lo tanto, las relaciones de poder remiten más allá de políticas impuestas por determinadas instituciones, estas relaciones están enraizadas en el sistema de las redes sociales. Pensar de este modo conlleva a ver que el poder no es "no está localizado en un lugar, es más bien el resultado de la interacción de fuerzas... el poder actúa produciendo verdades que se van institucionalizando, esto es, que se van volviendo prácticas, instituciones y sujetos. " (Álvarez, 2003. p. 275)

Teniendo en cuenta lo anterior, en el triángulo de las relaciones saber, poder, sujeto, se plantearon una serie de preguntas que posibilitaron identificar y realizar el análisis de los saberes pedagógicos que circulan en los maestros que enseñan Biología en torno a la botánica, tomando como referencia la relación sujeto, saber y poder.

De acuerdo a esta relación, es necesario tener claro que los sujetos se caracterizan por construir saberes cuya constitución da cuenta de determinadas prácticas y discursos que se consolidan a través de los trayectos. Es así, que se plantea el archivo como una herramienta metodológica entendida como "el sistema general de la formación y transformación de los enunciados". (Foucault, 1969, p 219), esta noción remite a prácticas y al conjunto de reglas que en una sociedad determinada establecen de qué hablar, cuáles son los enunciados válidos y qué individuos o grupos tienen acceso a determinados tipos de discurso y cómo están institucionalizadas las relaciones de poder entre quienes lo emiten o lo reciben.

Por lo tanto, se planteó dentro de la metodología algunos elementos como:

- Rastreo de documentos “...para analizar las prácticas de saber acoge los documentos, no tanto como fuente, sino como registro de prácticas, el documentos no es una fuente para hacerla hablar desde otra discursividad, es registro donde ya se ha hablado desde un ejercicio de saber, cruzado por instituciones, discursos, sujetos y prácticas diferentes, desde ahí que se asuma el documentos visto desde su discurso, como un tejido relacional que permite una reescritura metódica de lo dicho. (Zuluaga, 1999, p. 18)

- La observación participante la cual se puede definir como "la práctica de hacer investigación tomando parte en la vida del grupo social que se está investigando... el investigador es un actor en la situación social y puede...comprender el comportamiento. La observación participante es axiomática tanto en la enseñanza como en la investigación acción, ya que el profesional debe estar comprometido con el estudio de su práctica" (Mckernan, 1999, p.84). Las observaciones fueron registradas en el diario de campo, el cual fue tratado como un documento. 
- La entrevista entendiéndola como “ ...la conversación, el diálogo directo y espontáneo entre un entrevistador y un entrevistado con el fin de obtener una información importante para el estudio o explicación del problema de investigación" (Calvache, 2005,p.64), específicamente la entrevista no estructurada la cual es " flexible y abierta , aunque los objetivos de la investigación rigen las preguntas, su contenido, orden , profundidad y formulación...si bien el investigador, sobre la base del problema, los objetivos y las variables, elabora las preguntas antes de realizar la entrevista, modifica el orden, la forma de encauzar las preguntas o su formulación para adaptarlas a las diversas situaciones y características particulares de los sujetos de estudio. (Calvache, 2005, p.67). Las charlas o entrevistas fueron registradas a manera de documentos para su posterior tematización.

Desde la perspectiva anterior, la observación permite visibilizar las prácticas de enseñanza que existen en torno a la botánica y con ello dar cuenta del saber que han construido los maestros alrededor de ésta. Pues al tener en cuenta algunas aproximaciones al saber es pertinente visibilizar las relaciones de éste con las prácticas, es así que el cuestionarse por la consolidación de éstas implica pensar en las formas de existencia de un saber y por las condiciones que han permitido la circulación de determinados discursos, los cuales serán conocidos a profundidad mediante las entrevistas o charlas. En este sentido “...no se puede entender la práctica sin el saber y viceversa, es decir, práctica y saber son al mismo tiempo objeto y condición de posibilidad." (Zuluaga, et al, 2005, p. 20). Por consiguiente, no es posible entender el discurso por una parte y las prácticas por otra, pues es a través de las prácticas que los discursos se materializan.

Posteriormente, se recurrió a la tematización de los documentos mediante las fichas temáticas las cuales “Tienen como objetivo fundamental registrar la información temática de los documentos claves identificados durante la investigación. Se trata de un procedimiento metodológico que busca desarticular los textos en sus temáticas centrales o principales para posibilitar de esa manera cruces horizontales entre documentos de diverso tipo y nivel de los cuales deberán salir agrupamientos temáticos en los que sea posible ubicar cada uno de los documentos trabajados." (Castro, 2007, p.1).

Finalmente, se realizo una matriz con la información tematizada donde se dio cuenta de las regularidades que se presentaban en el discurso tanto de los maestros como de la información encontrada en otros documentos, rescatando así mismo aspectos que no eran regular en el discurso.

\section{RESULTADOS Y DISCUSIÓN}


A partir de la organización del archivo y de la lectura hipertextual realizada con base en las matrices, se exponen algunos apartados que dan cuenta de lo que circula en los maestros alrededor de la botánica en el marco de las ciencias naturales, sus condiciones de posibilidad considerando la relación saber, poder, sujeto. Así mismo, es importante anotar que no se buscó otorgarle un sentido a la información obtenida, por el contrario se permitió que el archivo mostrará lo que circula en torno a la problemática planteada, lo cual posibilita otras miradas y posicionamientos frente a ésta.

Igualmente, es válido aclarar que no se pretender realizar una generalización alrededor de la botánica en la escuela y su enseñanza, por el contrario lo que se muestra es una reflexión con base en lo trabajado en la práctica pedagógica y lo posibilitado por los maestros de biología y las instituciones educativas.

\section{LA BOTÁNICA: UNA MIRADA DESDE EL MAESTRO, LA ENSEÑANZA Y LAS RELACIONES DE PODER.}

\section{- Construcciones alrededor de la Botánica: ¿plantas o vegetales, ciencia o disciplina?}

Entrar a definir lo que se entiende por botánica en el siglo XXI en el contexto colombiano constituye una tarea compleja, pues en primera instancia existen grandes controversias entre sí es el estudio de las plantas o los vegetales o si constituye una ciencia o disciplina, pues “¿Qué es la botánica? Las respuestas serían entre otras: "es el estudio científico de las plantas", "es la ciencia que trata los vegetales", "es la ciencia que se refiere a la información básica relacionada con las plantas en general". Las definiciones anteriores podrían ser rebatidas por cuanto existen imprecisiones acerca de lo que se entiende por "plantas" o "vegetales" y además, no está claro el alcance de lo que se acepta como "ciencia" o "estudio científico". (Moreno, 2007)

Sin embargo, al realizar la indagación de saberes pedagógicos de los maestros que enseñan biología entorno a la botánica, se evidenció que ésta para la mayoría de ellos constituye una ciencia que está relacionada con el estudio de los vegetales y plantas para su clasificación taxonómica, el conocimiento de toda su fisiología y sus usos a nivel medicinal e industrial. Es así, que se observa que la botánica en gran parte solo es pensada desde un punto netamente biológico, pues se resaltan todas sus características a nivel fisiológico y estructural, dejando un poco de lado las relaciones sociales y culturales que los grupos humanos han establecido alrededor de ella. Tal y como lo decía un maestro es importante rescatar en la escuela "la relación plantas- comunidades humanas (cultura, historia usos y aplicaciones)" (Maestra A, 2010), pues es probable que a partir de esto se logre acercar a los sujeto a una comprensión de la botánica de una forma mucho más significativa.

Así mismo, si se realiza una mirada a lo que actualmente se entiende de botánica es muy posible encontrar que efectivamente esta constituye el estudio de las plantas y en diversos textos se le asume como ciencia o como disciplina de la biología, pero lo que si se tiene muy claro es que la botánica está constituida por varias ramas: la paleobotánica, estudia 
los restos vegetales fósiles; la geobotánica trata la distribución de la flora en las distintas áreas del planeta; la botánica pura ordena y clasifica las plantas; y la aplicada estudia las características de las plantas en relación con su empleo por el hombre, todos éstos aspectos que retoman los maestros dándole mayor prioridad a unos que a otros. Igualmente, es relevante destacar que la botánica establece toda una serie de relaciones con ciencias, como la geografía, la paleontología o la química, que resultan útiles para ampliar y profundizar sus conceptos, hecho que lo tienen claro los maestros pues para ellos es importante recurrir a la química o la física para lograr explicar procesos fisiológicos propios de las plantas.

De acuerdo a lo anterior, se evidencia que los saberes de los maestros entorno a la botánica hacen mayor énfasis en temas biológicos que en los sociales o culturales, pero el ¿por qué de esta situación? Para responder a este cuestionamiento fue necesario remitirse a los aspectos que han afectado la construcción de dichos saberes alrededor de la botánica, encontrándose que la formación de los maestros desde los colegios y universidades ha sido uno de los factores que ha llevado a que se piense lo botánico solo desde lo disciplinar dejando de lado otro tipo de relaciones que existen alrededor de las plantas.

Igualmente, otro factor a tener en cuenta en la construcción de este saber ha sido la experiencia práctica en donde los maestros afirman “...A esta construcción llegue por el acercamiento que tuve a la disciplina desde la práctica más que desde lo teórico" (Maestro A, 2010) lo cual da cuenta de la separación teoría - práctica que se tiende a realizar, aspecto que conlleva a pensar que la teoría es algo incompleto cuyo complemento seria la práctica. Sin embargo, teoría y práctica son una sola pues "no podría exigírsele ya más a la teoría que tuviese en cuenta la práctica, pues ella es en sí misma práctica; práctica que en un doble juego hace uso de herramientas teóricas a la vez que construye otras nuevas." (Zuluaga et al, 2006, p.10)

Por otro lado, se hace evidente que lo que circula en torno a la botánica en los maestros de Biología está determinado por una serie de lógicas sociales, políticas y económicas donde el abordaje de lo botánico en la escuela solo es pensado desde la mirada Biológica, pues se destacan exclusivamente unas formas de conocimiento que posibilitan y garantizan el futuro desenvolvimiento del estudiante en una sociedad capitalista y globalizada.

Es así, que lo que circula en la escuela en torno a la Botánica esta mediado por la forma como los maestros apropian ese saber y como a partir de la enseñanza lo reestructuran, le dan otro matiz, otro significado. Esto lleva a pensar que los maestros si saben de botánica, tendiendo como base algunos conceptos y relaciones que han sido posibles gracias a la enseñanza y a la reflexión de su práctica pedagógica.

• ¿Qué enseñar de Botánica? Relaciones de fuerza y sujetos.

\section{"...la botánica ya como que ni se enseña..."}


Al realizar una mirada hacia la historia se evidencia que la botánica tuvo gran auge a mediados de los siglos XVII y XVIII pues “...la investigación botánica y, por ende, su enseñanza se vio favorecida por el interés de los gobiernos europeos por conocer los recursos de sus naciones para obtener mayores riquezas y ejercer un control más eficaz en sus territorios, siendo éste el principal incentivo que permitió una mayor consideración del reino vegetal, lo cual contribuyó, de paso, al florecimiento de la botánica en Europa y sus colonias durante el siglo XVIII." (Correa, 2010, p.17).

Así mismo, al cuestionarse por la botánica en la escuela a mediados del siglo XVIII se encuentra que esta era parte fundamental de la Historia Natural y que mediante el conocimiento de las plantas era posible acercarse a la comprensión de aspectos relacionados con la zoología, pero entonces ¿qué paso para que actualmente la botánica se esté dejando de lado? Pues como según lo afirman los maestros “... la botánica se ha dejado de lado, la botánica ya como que ni se enseña... y la botánica es importante que de pronto una química o física porque es que es nuestro medio, pero se ha dejado de lado y no le dan importancia "(Maestra C, 2010)

De esta forma, la enseñanza de la botánica en la escuela retomando algunos aspectos históricos se ha visto atravesada por determinadas relaciones que han propiciado su actual desplazamiento del currículo por otros saberes más útiles en contexto. Es así, que pensar en la enseñanza de la botánica implica visibilizar toda una serie de relaciones de poder y condiciones de posibilidad que son las que permiten el que circule algo entorno a lo botánico o no.

De acuerdo a lo anterior, antes de continuar, es necesario hacer algunas aclaraciones sobre el poder, toda relación de fuerzas es una «relación de poder». "Eso quiere decir, en primer lugar, que el poder no es una forma... es «un conjunto de acciones sobre acciones posibles». Se puede, pues, concebir una lista...que expresan una relación de fuerzas o de poder y que constituyen acciones sobre acciones: incitar, inducir, desviar, facilitar o dificultar, ampliar o limitar, hacer más o menos probable." (Deleuze, 1987, p.99) Por lo tanto, se evidencia que las relaciones de fuerza no solo promueven la circulación de un discurso o práctica, sino que condicionan algunas dinámicas.

Entonces es pertinente, preguntarse si realmente se enseña botánica en la escuela, a lo cual debido a las observaciones y charlas con los maestros se puede decir que se enseñan algunos saberes relacionados con ella, abordándose fundamentalmente cuestiones taxonómicas, fisiológicas y ecológicas de las plantas. Es así, que se observa un desplazamiento de la botánica en el currículo, donde lo imperativo es la enseñanza de determinados contenidos que conlleven a que el estudiante sea competitivo y logre hacer en contexto. 
Todas estas lógicas y dinámicas han determinado que saberes relacionados con botánica se enseñan, aspecto que ha sido ampliamente analizado por los maestros a tal punto que afirman que " Mirar por qué se enseñan ciertos aspectos de botánica implica remitirse a lo que se determina desde el ministerio de educación, pues aquí se acoge desde los estándares” (Maestra E, 2010)...“De todas formas pues la gente que está arriba, porque eso viene de arriba, a veces del Banco Monetario o a veces del mismo sistema, porque pedagogos son muy pocos los que están metidos en el cuento" (Maestra C, 2010). Es así, que se visibiliza toda una trama de relaciones que afectan el ser y quehacer del maestro, relaciones de fuerza que permean la enseñanza en la escuela.

Sin embargo, la enseñanza de la botánica no solo se ve afectada por políticas ministeriales o por la misma dinámica del sistema económico actual, sino por los mismos intereses de las instituciones educativas a tal punto que la administración de éstas, constituye un elemento a tener en cuenta al momento de pensar la enseñanza, así lo afirma un maestro “Cuando llega una nueva administración todo cambia, se pasó del aula verde a la parte de la biotecnología enfocada en las plantas... Con esa administración no se vieron los beneficios que tenía el trabajar desde espacios como el aula verde, entonces todo ha quedado en intentos... no destinan dinero a lo botánico porque no le ven la importancia... todo se mide por los resultados." (Maestra E, 2010)

De acuerdo a lo anterior, se muestra como el ser y quehacer del maestro en diversas ocasiones es afectado por relaciones de poder que le imponen determinadas funciones, sin embargo, es mediante la reflexión constante y la investigación pedagógica que el maestro puede hacer de su práctica un espacio donde se problematice toda esta serie de relaciones y donde dirija la mirada a sí mismo y hacia la enseñanza, ésta entendiéndola no como las formas de enseñar ni reduciéndola a una práctica intersubjetiva, por el contrario entender la enseñanza como una posibilidad de pensamiento donde es necesario "intentar un acercamiento a los acontecimientos de saber que ocurren en la enseñanza, pensar la enseñanza como acontecimiento de saber y poder...se trata de construirla como punto de resistencia contra el poder normalizador que constriñe el pensamiento...pensar la enseñanza como acontecimiento implicaría entonces exorcizarla de toda exigencia funcional u operativa..." (Martínez, 2003, p.211).

\section{LA ENSEÑANZA DE LA BOTÁNICA EN LA ESCUELA}

\section{- Contenidos alrededor de la Botánica abordados en la escuela y su importancia.}

Las tendencias contemporáneas de la complejidad y la interdisciplinariedad han permeado la manera en la que se concibe la ciencia, es así, que en el discurso de las 
ciencias naturales se han integrado diversas perspectivas de lo vivo y su dinámica, miradas que se han extrapolado a la escuela y que han configurado un acercamiento particular a la comprensión de los sistemas vivientes y a las relaciones que establece con su medio.

Por lo tanto, al realizar una mirada al área de ciencias naturales en la escuela y a los contenidos que esta abarca con base en los planes de estudio facilitados por las instituciones, se encontró una tendencia a clasificar los mismos en relación a tres categorías específicas: animales, plantas y humanos. Es así, que en lo concerniente a los contenidos en torno a lo botánico se encontró que existe una regularidad que se inclina por el desarrollo de temáticas tales como "“Las plantas. Reconocimiento y partes de la planta."... “Las plantas. Partes y funciones de las plantas. Cuidados con las plantas."... "Las plantas. Etapas del desarrollo de plantas"... " Histología: diferencia entre tejidos animales y vegetales", aspectos que abarcan aspectos netamente biológicos, siendo el más fuerte lo relacionado con lo taxonómico, en donde los maestros hacen mucho énfasis a sus estudiantes en la importancia de la clasificación para el reconocimiento de la biodiversidad.

Igualmente, los maestros se inclinan por abordar aspectos que den cuenta de la estructura de la planta y su fisiología, pues así lo expresan “"La estructura y de la planta, sus funciones y la relación entre ellas en diferentes procesos como la reproducción, crecimiento y desarrollo, el metabolismo: porque permite abordar algunos conceptos así comparar con las estructuras y procesos de otros organismos." (Maestra A, 2010)

Así mismo, fue interesante encontrar que la gran mayoría de los maestros establecen relaciones entre la botánica y la ecología, donde lo relevante es lograr comprender el tipo de interacciones que existen entre las plantas y su medio. Es así, que algunos maestros comentan "La botánica uno la miraba como el estudio de las plantas pero en este momento se debe incluir mucho a la ecología, a la parte del medio ambiente"... "La relación de las plantas con su medio (condiciones ambientales y otros organismos). Servicios ambientales" (Maestra A, 2010), saberes que están muy relacionados con lo que expresa Álvarez, et al (1998) "Los vegetales son considerados como parte integral de nuestro ambiente y en forma más específica como productores en los ecosistemas, por lo tanto es imperativo para el hombre, el estudio y conocimiento de estos organismos..." p. 68. Por lo tanto, se logra evidenciar otro aspecto interesante a desarrollar y trabajar cuando se lleva la botánica a la escuela.

Por otro lado, se visibilizan otros contenidos o temáticas a trabajar, las cuales no se presentan con la misma frecuencia y fuerza que las anteriormente nombradas, siendo estas las que hacen referencia a "La relación plantas comunidades humanas (cultura, historia usos y aplicaciones)" (Maestra A, 2010), un factor que es importante rescatar e incluir en la enseñanza de esos saberes relacionados con la botánica, pues permite dirigir la mirada a ésta desde otros lugares estableciendo otro tipo de relaciones con el conocimiento. 


\section{¿Cómo se enseña lo botánico? Reflexiones a propósito de la didáctica}

Muchas de las maneras cómo los maestros enseñan o abordan algunos contenidos en la escuela vienen determinadas por su experiencia académica y profesional, pues a través de éstas toman elementos que les permiten pensar la enseñanza y de acuerdo a ello generan situaciones en donde los estudiantes problematicen y cuestionen el conocimiento.

Por otro lado, se ha encontrado que en cuanto “...al estudio y enseñanza de los vegetales en Colombia históricamente, ha sido realizado por profesionales especializados solamente en el campo de la botánica sin formación profesional en pedagogía, haciendo énfasis inicialmente en lo descriptivo y muy recientemente en lo fisiológico molecular, con tendencia transmisionista." (Álvarez, et al, 1998 p. 68) Razón por la cual los maestros proponen que para lograr que el estudiante se acerque a la comprensión de lo botánico, se recurra a realizar diversas actividades, tales como recorridos en las zonas verdes de la institución educativa, pues a partir de ahí se establecen relaciones con la cotidianidad del estudiante para así posteriormente, acercarlo al conocimiento científico de las plantas. Así mismo, se plantea que la enseñanza de la botánica se caracterice por tomar elementos propios del contexto de los estudiantes, para así lograr un reconocimiento de su entorno.

Otro elemento que se contempla a la hora de enseñar la botánica son las salidas de campo, en donde el estudiante tiene la posibilidad de reconocer e identificar características propias de las plantas, además, de constituir otro escenario en el cual tanto maestros como estudiantes logran acercarse a éstas de una manera diferente.

\section{- La botánica desde los saberes populares y ancestrales}

La posibilidad de abordar la botánica en la escuela mediante las relaciones que establecen determinados grupos humanos con las plantas y la utilidad de las mismas, reconociendo la importancia que éstas tienen en la vida del hombre y en el mantenimiento del equilibrio dinámico de los ecosistemas ha cobrado gran importancia actualmente. Por tal razón, un maestro afirma que "La botánica se podría trabajar desde otros ángulos por ejemplo mirando el impacto ecológico...es importante reconocer lo de la zona, por ejemplo los indígenas como aprovechan las plantas y mirar también todo lo que han construido alrededor de ellas." (Maestro E, 2010). Así mismo, se destacan ideas como "La enseñaría (la botánica)...desde el planteamiento de problemáticas y la indagación de los saberes populares y ancestrales." (Maestro A, 2010)

De acuerdo a lo anterior, se puede ver como a través de la enseñanza de la botánica se logra el rescate y reconocimiento de los saberes populares y las tradiciones que poseen algunas comunidades humanas, esta idea conlleva a pensar en la etnobotánica y cómo "los aportes de esta...trascienden de los simples listados taxonómicos de plantas útiles hacia la concepción que se posee...sobre el entorno vegetal y el bagaje cultural, con el fin de despertar en las nuevas generaciones el interés por reconocer sus raíces culturales y fortalecer su identidad..." (Gonzales y Mora, 2009). 


\section{La enseñanza de la botánica: un pretexto para el desarrollo de competencias científicas}

La clase de Biología se ha consolidado como el mejor espacio para abordar temáticas relacionadas con la botánica, es así que desde esta se desarrollan y trabajan contenidos encaminados a desarrollar cierto tipo de habilidades en los estudiantes, en este caso específicamente de las competencias científicas, las cuales hacen referencia a la capacidad del individuo para apropiarse, adaptar, transformar los conocimientos y herramientas de pensamiento que proveen las ciencias naturales para la comprensión del mundo y la solución de problemas de la vida real.

De acuerdo a esto, el estudio de las plantas puede ser un pretexto para abordar diferentes conceptos y problemáticas, sobretodo porque en la educación básica y media, las plantas casi no se involucran en clase, además para desarrollar diferentes habilidades en los estudiantes como la observación, el registro de datos y la construcción de explicaciones. Es así, que varios maestros comentan que el trabajo de la botánica se presta para que “... los estudiantes hacen ensayos, con experimentos y mirar y tomar datos y entonces eso hace como que los niños desarrollen su pensamiento científico, cuando toma datos, hace inferencias, elabora conclusiones y realizan análisis..." (Maestro D, 2010) .Por lo tanto, se evidencia como muchas actividades como la elaboración de escritos, las prácticas de campo y de laboratorios alrededor de la botánica contribuyen a que los estudiantes estructuren hipótesis, realicen observaciones, conclusiones y análisis, lo que contribuye al desarrollo del pensamiento científico y de ciertas habilidades.

Así mismo, se destaca que “...es indispensable para la enseñanza de la botánica, a cualquier nivel, la realización de prácticas que involucren la elaboración de ilustraciones científicas de las plantas, con el fin de promover en los alumnos una observación cuidadosa, necesaria para el aprendizaje eficaz de este grupo de organismos. De ahí la importancia de retomar el trabajo iconográfico de la Expedición Botánica de la Nueva Granada y adaptarlo a la enseñanza de la diversidad vegetal en nuestro país." (Correa, 2010, p.19). Lo anterior, da cuenta de la utilidad y relevancia de rescatar las ilustraciones botánicas, lo cual normalmente no se considera un elemento para pensar la botánica en la escuela de otra manera, es así, que este tipo de actividades puede llegar a desarrollar la creatividad en los estudiantes, así como la capacidad de observación de los mismos.

Igualmente, se contempla que la ilustración botánica puede favorecer el desarrollo de determinadas competencias científicas básicas tal y como lo afirma Correa (2010) "Entre las competencias científicas básicas que se pueden desarrollar en los estudiantes a través de la actividad de la ilustración botánica se encuentran las siguientes...Capacidad de observar y describir objetos... Manipular instrumentos de medida y habilidad para realizar mediciones de diferentes magnitudes. Estas dos competencias son necesarias para la elaboración de dibujos a escala de las diferentes estructuras o del ejemplar completo.... Capacidad para seguir instrucciones...Habilidad para recolectar datos. La cual es fundamental para registrar en una representación las características del espécimen más 
importantes ... Reconocer y emplear un lenguaje científico....Este sistema también se puede emplear en la enseñanza de la botánica, pues le facilita al estudiante relacionar cada estructura representada de la planta con la correspondiente terminología botánica...Capacidad para trabajar en grupo. Esta habilidad fue crucial...para la creación de la inmensa obra iconográfica, en la cual se observa el trabajo conjunto de los herbolarios, los dibujantes y los botánicos." (Correa, 2010, p.21)

De acuerdo a lo anterior, se puede decir que la botánica actualmente en las instituciones trabajadas, se toma como un pretexto para desarrollar determinadas competencias que responden a las lógicas capitalistas y globalizantes de la sociedad. Esta manera de concebir la botánica se puede evidenciar en el más reciente y conocido proyecto "Expediciones Botánicas s. XXI" el cual se caracteriza por ser un programa promovido por el Ministerio de Educación para el desarrollo de las competencias científicas, la enseñanza y aprendizaje de las ciencias naturales, en donde lo que se pretendía era vincular la comunidad educativa de Colombia para promover el desarrollo de competencias científicas, a partir de proyectos de aula, en torno a la investigación y aplicación de procesos, con la botánica como protagonista. Es así, que si se puede hablar de una enseñanza de la botánica pero donde es necesario aclarar que ésta, está encaminada solo a determinados saberes relacionados con ella y a alcanzar fines que responden a la dinámica social, económica y política actual.

\section{¿OTRAS POSIBILIDADES PARA PENSAR Y ABORDAR LA BOTÁNICA?}

A lo largo del documento ya se han expuesto diversas ideas que apuntan a la didáctica de la botánica, las cuales llevan a pensar que es posible el abordaje de algunos saberes relacionados con ésta en la escuela, en donde se le permita al estudiante el cuestionar y problematizar el conocimiento al cual tiene acceso y donde el maestro piense y estructure diversas estrategias para lograr acercar al estudiante al conocimiento de lo botánico, y así mismo, posibilite otras miradas hacia ésta dinamizando lo que circula de ella en el ámbito educativo.

El pensar una didáctica de la botánica ha sido una tarea realizada por diversos investigadores y pedagogos, que plantean ciertas herramientas o estrategias como la elaboración de herbarios, la elaboración de huertas o colecciones botánicas. Sin embargo, es prudente dirigir la mirada hacia la botánica de otra manera, donde no sólo se haga énfasis en determinados contenidos o aspectos exclusivamente biológicos, sino donde se posibilite visibilizar otras relaciones que existen alrededor de lo botánico, donde se permita la pregunta por el sujeto y por el saber.

Así mismo, sería pertinente que la enseñanza de la botánica en la escuela deje de lado el carácter transmisionista que se le otorga, y posibilite el desarrollo de un pensamiento crítico que logre rescatar las relaciones culturales y sociales que emergen alrededor de la botánica, si bien, es importante el conocimiento de la estructura y fisiología de las plantas 
para lograr comprender las interacciones que establecen con su medio, ¿por qué no posibilitar otro tipo de acercamientos a la botánica?

Por otro lado, pensar la botánica desde el marco de las ciencias naturales le confiere ciertas particularidades que permean su enseñanza, a tal punto que es escaza la información que se encuentra en torno a la enseñanza de la botánica como tal pues se tiende a incluir ésta dentro de la enseñanza de las ciencias. Por tanto, los saberes relacionados con la botánica circulan fugazmente dentro de las ciencias naturales, se le asignan otros significados y se configuran otro tipo de relaciones con el conocimiento debido al discurso de la interdisciplinariedad e integración de las ciencias.

Finalmente, se establece una apuesta a pensar y problematizar el lugar común que se le ha otorgando a los saberes alrededor de la botánica y a su enseñanza, teniendo en cuenta el marco actual de las ciencias naturales, al lugar que se le otorga al maestro de Biología y a la investigación pedagógica, como un ejercicio de pensamiento que posibilita la emergencia de otros lugares y miradas que logran configurar el ser y quehacer del maestro.

\section{CONSIDERACIONES FINALES}

La botánica en gran parte solo es pensada desde un punto netamente biológico, pues se resaltan todas sus características a nivel fisiológico y estructural, dejando un poco de lado las relaciones sociales y culturales que los grupos humanos han establecido alrededor de ella, los cuales posiblemente permitirían un acercamiento mucho más significativo a las plantas por parte de los estudiantes.

Sin embargo, se hace evidente que lo que circula en torno a la botánica en los maestros de Biología está determinado por una serie de lógicas sociales, políticas y económicas donde el abordaje de lo botánico en la escuela solo es pensado desde la mirada Biológica, pues se destacan exclusivamente unas formas de conocimiento que posibilitan y garantizan el futuro desenvolvimiento del estudiante en una sociedad capitalista y globalizada.

De esta forma, la enseñanza de la botánica en la escuela retomando algunos aspectos históricos se ha visto atravesada por determinadas relaciones que han propiciado su actual desplazamiento del currículo por otros saberes más “útiles” en contexto. Es así, que pensar en la enseñanza de la botánica implica visibilizar toda una serie de relaciones de poder y condiciones de posibilidad que son las que permiten la circulación de algo entorno a lo botánico o no.

Por otro lado, es necesario destacar como el saber pedagógico le da ciertos elementos al maestro configurando determinadas relaciones en torno a la enseñanza, la práctica pedagógica y en general al ser y quehacer del maestro, posibilitando la mirada a determinadas lógicas educativas desde otros escenarios y lugares. Es así, que la pregunta por el saber pedagógico contribuye a generar todo un tipo de reflexiones donde el maestro 
dirige la mirada a sí mismo y una serie de dinámicas que le asignan un significado a su labor.

Finalmente, es pertinente el cuestionarse sobre el lugar de la botánica en la escuela, en las ciencias naturales y en el aula. ¿Qué otras maneras posibilitan que lo botánico circule entre los maestros con una mirada diferente a la actual?, ¿Por qué utilizar la botánica como un pretexto para desarrollar competencias científicas? ¿ ¿Por qué no rescatar esos saberes tradicionales que existen en torno a la botánica y otras relaciones que emergen alrededor de ella? , ¿Qué factores han contribuido al desplazamiento de la botánica en el currículo escolar?

\section{BIBLIOGRAFÍA}

Álvarez, A. Arias, H. (1998). El aprendizaje de algunos conceptos fundamentales en el campo de la Botánica. En: Revista TED n ${ }^{\circ}$. Facultad de Ciencia y Tecnología. Universidad Pedagógica Nacional. Bogotá.

Álvarez, A. (2003). Medios de Comunicación y la sociedad educadora ¿Ya no es necesaria la escuela? Cooperativa Editorial Magisterio. Bogotá.

Calvache, J. (2005). La investigación una alternativa pedagógica y didáctica en la formación profesional. Universidad de Nariño. San Juan de Pasto.

Castro, J. O. (2007). La ficha analítica y la ficha temática: Soportes para el trabajo documental. Documento de trabajo. Bogotá

Correa, A. Mutis y La Expedición Botánica de La Nueva Granada: Revisión de Los orígenes de La Enseñanza de la Diversidad Vegetal en Colombia. En: Revista Bio-grafia: Escritos sobre la Biología y su Enseñanza Vol. 3 No4. Departamento de Biología. Universidad Pedagógica Nacional.

Colegio CAFAM. Estructura curricular. (2010). Plan de estudios del área de ciencias naturales y educación Ambiental. Bogotá.

Deleuze, G. (1987). Foucault. Editorial Paidos. Buenos Aires.

Gonzales, B. Mora, M. (2009). Estudio etnobotánico de las plantas medicinales empleadas por la comunidad rural de Zaque Municipio de Gachetá, Cundinamarca. En: Revista TED n 9. Facultad de Ciencia y Tecnología. Universidad Pedagógica Nacional. Bogotá.

Hannu, S. et al. Un catálogo de posibilidades: historia Foucaultiana de investigación de la verdad y la educación.

Klaus, A. (2002). Una epistemología histórica de la pedagogía: el trabajo de Olga Lucia Zuluaga. En Pedagogía v. $23 \mathrm{n}^{\circ} 68$. Caracas.

Lugo, M. (2002). Saber y poder: una relación compleja. En: La Lámpara de Diógenes. Vol. 3, Nº06. Universidad Autónoma de Puebla. México.

Maestro A, C, D, E. (2010).

Martínez, A. Unda, M. Maestro: sujeto de saber y prácticas de cualificación. Tomado el 28 mayo de 2010. De: http://www.pedagogica.edu.co/storage/rce/articulos/rce31 08inve.pdf

Martínez, A. (2003). La enseñanza como posibilidad del pensamiento. En: Pedagogía y epistemología. Cooperativa Editorial Magisterio. Bogotá.

Moreno, A. Et al. (2006). Tras las huellas del saber pedagógico. Universidad Pedagógica Nacional. Bogotá.

Moreno, E. Tamayo, F. (2007). El Herbario como recurso para el aprendizaje de la botánica. En Acta botánica. Caracas. 
Osorio, A. Et al. (2009). La botánica, la enseñanza y la escuela: discursos, prácticas y sujetos. Línea de investigación trayectos y aconteceres: estudios del ser y el quehacer del maestro desde la pedagogía Departamento de Biología. Universidad Pedagógica Nacional. Bogotá.

Roa, P. Herrera, J. (2010). Trabajo de grado para optar al título de Magister en Educación. Historia de los saberes escolares: la emergencia de la biología en la escuela colombiana 1900 - 1930. Universidad Pedagógica Nacional. Bogotá.

Zuluaga. L. (1999). Pedagogía e historia. La historicidad de la pedagogía, la enseñanza un objeto de saber. Anthropos. Antioquia.

Zuluaga, L. Grupo de historia de la práctica pedagógica. (2005). Foucault, la pedagogía y la educación. Pensar de otro modo. Cooperativa Editorial Magisterio. Bogotá. 